\title{
Experience in a Pediatric Prolonged Mechanical Ventilation Unit from a public hospital in Chile
}

\author{
Daniel Zenteno, M.D. ${ }^{a, b}$, Gerardo Torres-Puebla, Kinesiologist and MSc, ${ }^{a, c}$, \\ Ximena Navarro, Kinesiologist ${ }^{a}$, Carla Rivas, Registered Nurse ${ }^{a}$, Jaime Tapia, M.D. ${ }^{a}$, \\ Iván Rodríguez-Núñez, Kinesiologist $P h D^{c}$ and Javier Cepeda, M.D. ${ }^{a}$
}

\begin{abstract}
Introduction: Hospitalized patients with high respiratory technology dependency are increasingly common and result in lengthy stays in intensive care units. Strategies mitigating its impact have been scarcely described.

Objective: To describe a 6-year experience in a Pediatric Prolonged Mechanical Ventilation Unit. Methods: Retrospective study. All children admitted to the unit between October 2012 and December 2018 were included. Descriptive and inferential statistical methods were used, analyzing lengths of stay and readmissions. Different outcome measures were compared according to the type of pathology and

GLOSSARY

CLD: chronic lung disease.

CRD: chronic respiratory disease.

DS: Down syndrome.

IV: invasive ventilation.

NIV: non-invasive ventilation.

ND: neurological damage.

NMD: neuromuscular disease.

PICU: pediatric intensive care unit.

PMVU: prolonged mechanical

ventilation unit.

UAO: upper airway obstruction.
\end{abstract} mechanical ventilation.

Results: A total of 113 patientshad 310 admissions to the unit. Age at admission: 2.2 years (0.6-8.8); males: $60.2 \%$. Pathologies: neuromuscular disease $(22.1 \%)$, chronic lung disease $(20.4 \%)$, neurological damage (34.5\%), upper airway obstruction $(9.7 \%)$, heart disease $(3.5 \%)$, Down syndrome $(9.7 \%)$. A total of 10507 bed-days were used; with a $92.6 \%$ occupancy rate, $54.8 \%$ of transfers to the intensive care unit, and $66.1 \%$ of readmissions. Mean length of stay: 16 days (6.549.0); differences in age at admission observed by pathology $(p=0.032)$. More readmissions were observed in children with neurological damage and Down syndrome $(p=0.004)$. Children with invasive ventilation were observed to have a longer length of stay $(p<0.001)$ and more readmissions $(p<0.001)$.

Conclusion: The occupancy rate at the PMVU was over $90 \%$, which allowed more available intensive care beds and discharging all patients. Children with invasive ventilation had a longer length of stay and more readmissions.

Key words: mechanical ventilation, home health care, chronic respiratory diseases, tracheostomy, pediatrics.

http: / / dx.doi.org/10.5546/ aap.2021.eng.25

To cite:ZentenoD, Torres-Puebla G, Navarro X, Rivas C, et al. Experience in a Pediatric Prolonged Mechanical Ventilation Unit from a public hospital in Chile. Arch Argent Pediatr 2021;119(1):25-31.

\section{INTRODUCTION}

The advances made in pediatric and neonatal intensive care units, the use of more effective treatment regimens, and the development of programs focused on child health interventions have helped to increase survival among children with chronic respiratory diseases (CRDs). These patients require technological resources and a high level of professional specialization for an adequate diagnosis, treatment, and follow-up of their condition. ${ }^{1,2}$

This reality favors the hospitalization of these patients in tertiary care units, such as pediatric intensive care units (PICUs), with lengthy stays, which reduces the rotation of acute complex patients in critical condition in the health care network and increases direct costs and the health care opportunity cost. ${ }^{3}$ Implementing innovative and effective alternatives for the in-hospital management of these patients with CRDs is a challenge for health care models. ${ }^{4,5} \mathrm{~A}$ high percentage of these children require prolonged mechanical ventilation, defined as needing invasive or non-invasive ventilation during more than 21 days for more than 6 hours per day with interruptions of up to 48 hours. ${ }^{6}$ 
Reported experiences, both locally and internationally, suggest that ventilation can be initiated at the hospital and continued at the patient's home. This requires reducing the probability of adverse events, as well as ensuring the social inclusion of the child and their family, which entails the need for technological equipment, trained staff, training patients' parents and caregivers, and doing a follow-up.,

In Chile, the prevalence of children with CRDs has increased significantly in the last 20 years, and this has propelled the creation of governmental programs for the treatment, rehabilitation, and support of specific technological needs ${ }^{8-10}$ In this context, the Prolonged Mechanical Ventilation Unit (PMVU) was created in 2012, with 5 beds in the Division of Pediatrics of Hospital Guillermo Grant Benavente, in the city of Concepción. Since its creation, the PMVU was targeted at providing multidisciplinary care for children with complex CRDs by a multidisciplinary team made up of staff nurses and kinesiologists; with the support of speech therapists, occupational therapists, social workers, and a psychologist, and coordinated by a pediatrician specialized in bronchopulmonary conditions. The team requests regular assessments conducted by multiple medical specialists (ear, nose, and throat specialist, neurologist, endocrinologist, ophthalmologist, and surgeons), which allows the transition between the PICU and the patient's home, with the delivery of educational and clinical rehabilitation tools in order to ensure a safe and effective hospital discharge. ${ }^{3,11}$ More complex exacerbations with poor clinical course are referred to the PICU.

The objective of this study was to describe the experience at the PMVU of the Division of Pediatrics of Hospital Guillermo Grant Benavente, the characteristics of admitted patients and their readmissions, after 6 years of operation.

\section{METHODS}

This study is a retrospective case series, written according to the Strengthening the Reporting of Observational Studies in Epidemiology (STROBE) Statement. ${ }^{12}$ All children admitted to the PMVU from its opening (October 2012) to December 2018 were included. Figure 1 shows the flow chart of admissions, discharges, and readmissions at the PMVU. No exclusion criteria were defined.

The reason for admission to the PMVU was categorized as follows: (a) initiation of mechanical ventilation: patients admitted in order to assess the need for home invasive ventilation (IV) or noninvasive ventilation (NIV) and receive training on oxygen therapy, aerosol therapy, mechanical ventilation and artificial airway care, respiratory exercises and basic cardiopulmonary resuscitation, in charge of a multidisciplinary team, with brochures, handbooks, and theoretical-practical activities organized by trained staff; (b) scheduled multidisciplinary re-assessment: patients admitted in order to be assessed by multiple specialists; (c) post-exacerbation: clinically stable patients admitted after a respiratory or non-respiratory exacerbation, coming from critical care units or the emergency department; (d) decannulation process: patients with a tracheostomy admitted to start or adapt their decannulation plan; (e) medical or surgical procedure: patients with chronic respiratory conditions admitted for medical or surgical procedures without fulfilling the abovementioned reasons.

Upon admission to the PMVU, the demographic outcome measures of patients were recorded, such as age, sex, diagnosis, referring unit, type of mechanical ventilation (IV, NIV), reason for admission, and length of hospital stay in days. The admission diagnosis was classified into neuromuscular disease (NMD), chronic lung disease (CLD), central neurological damage (ND), upper airway obstruction (UAO), heart disease, and Down syndrome (DS).

\section{Statistical analysis}

Data were analyzed using the KolmogorovSmirnov normality test. Normal distribution was ruled out and quantitative outcome measures were expressed as median and interquartile range, qualitative outcome measures as percentage, and the Kruskal-Wallis test was used to compare length of stay in days, number of admissions, and readmissions by diagnosis and type of mechanical ventilation. In addition, the occupancy rate was expressed as percentage and determined by dividing the total number of occupied bed-days in a certain period by the total number of available beds in the same period. ${ }^{8}$

The analysis was done using the IBM SPSS Statistics ${ }^{\circledast}$ software for Windows, v23.0 (IBM Corporation, Armonk, New York, USA), and a value of $p<0.05$ was considered significant. The study was approved by the Ethics Committee of Universidad de Concepción. Data were entered into a spreadsheet with no identifiable personal history and coded, and the file was password protected. 


\section{RESULTS}

During the 6 years considered, 113 children were admitted to the PMVU, age at admission was 2.2 years $(0.6-8.8)$, and $60.2 \%$ were males (Table 1). NMD was observed in $22.1 \%$ of the sample; CLD, in $20.4 \%$; ND, in $34.5 \%$; UAO, in $9.7 \%$; heart disease, in $3.5 \%$; and DS, in $9.7 \%$ (Table 1).

Of the 113 admitted children, $87.6 \%$ were assessed for mechanical ventilation initiation and, finally, $61.9 \%$ of all patients required prolonged invasive or non-invasive ventilation. Out of all patients, 38 children were only admitted for the initial assessment, with no readmissions. The remaining 75 children were readmitted for different reasons: 36 for a re-assessment, 56 for an exacerbation, 6 for decannulation planning, and 9 for medical or surgical procedures (Table 2).

The 5 beds available at the PMVU allowed 310 admissions in the study period, with a total of 10507 bed-days and a $92.6 \%$ overall occupancy rate. Of these admissions, $46.1 \%$ were directly referred from critical care unit beds (intermediate or intensive care), who accounted for 8577 beddays, with a 17-day stay (7-44). Of all admissions, $63.9 \%$ corresponded to readmissions; $73.2 \%$ of which were post-exacerbation; of the latter, $84.8 \%$ were due to respiratory conditions; and $15.2 \%$, for other reasons. In the first year after being discharged, $38.9 \%$ of patients were readmitted.

FIGURE 1. Flow chart of admissions, discharges, and readmissions at the Prolonged Mechanical Ventilation Unit.

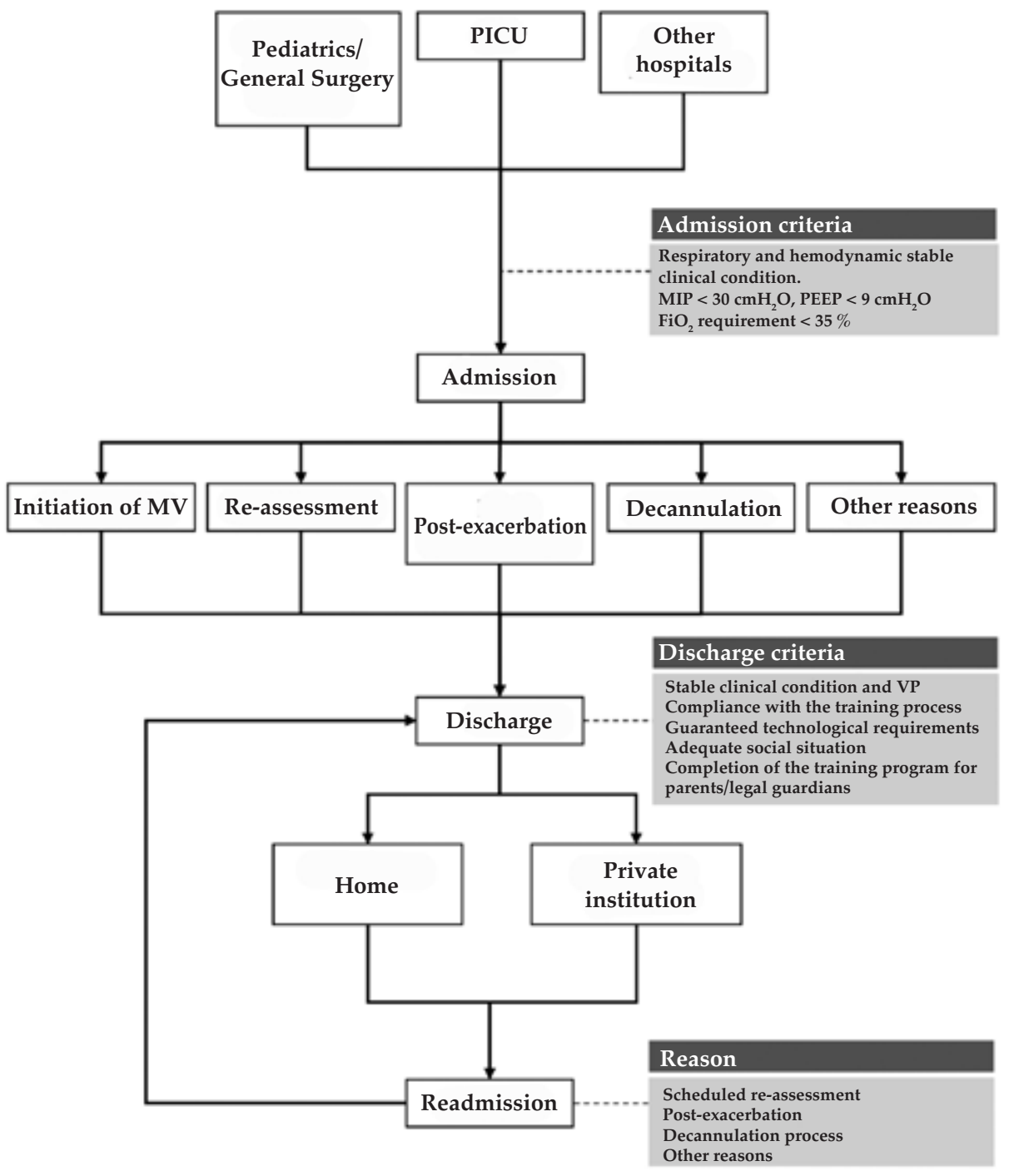


In the total sample, differences were observed in the age at admission to the PMVU; UAO was seen in younger patients and NMD, in older ones $(p=0.032)$. Children with ND and DS had a longer length of stay compared to other categories; whereas NMD patients had a shorter length of stay $(p=0.169)$ (Table 1$)$.

In the analyzed period, a median of 2 readmissions was observed in children with ND and DS ( $p=0.004)$; whereas the greatest number of post-exacerbation readmissions was seen in children with CLD, ND, and UAO, with a median of $1(p=0,046)$. Table 2 shows admitted and readmitted children by pathology subgroup.

According to the type of mechanical ventilation, differences were observed among the groups regarding length of stay $(p<0.001)$, number of readmissions $(p<0.001)$, number of re-assessments $(p=0.001)$, post-exacerbation readmissions $(\mathrm{p}<0.001)$, and readmissions due to medical or surgical procedures $(\mathrm{p}=0.018)$; children with IV had a longer length of hospital stay and more readmissions than the other groups (Table 3). A successful decannulation process was observed in $18 \%$ of the patients in this group.
Among children with NIV, post-exacerbation hospitalizations were less common and were mainly due to respiratory conditions in $79.7 \%$ of admissions. Elective hospital admissions were related to more invasive procedures, such as the need for gastrostomy $(1.6 \%)$ or multidisciplinary re-assessments, when faced with complex cases difficult to assess at the outpatient offices $(16.4 \%)$.

A total of $99 \%$ of children were discharged from the hospital and sent home or to a private institution in cases of patients struggling with social determinants; and, out of patients requiring home ventilation upon discharge, $47.1 \%$ corresponded to IV and $52.9 \%$, to NIV. The length of hospital stay was 16.0 days (6.549.0). Only one child with IV died at the PMVU; he received palliative care due to the advanced state of his underlying condition.

\section{DISCUSSION}

This article reports a 6-year experience at a PMVU from a public hospital in Chile, which included study and treatment respiratory strategies, individualized rehabilitation, and training for parents and caregivers. During the

TABLE 1. General characteristics of the total sample and by pathology subgroup in the first admission, expressed as median and interquartile range

\begin{tabular}{|c|c|c|c|c|c|c|c|}
\hline $\begin{array}{l}\text { Outcome } \\
\text { measures }\end{array}$ & $\begin{array}{c}\text { Total } \\
(n=113)\end{array}$ & $\begin{array}{l}\text { NMD } \\
(n=25)\end{array}$ & $\begin{array}{c}\text { CLD } \\
(n=23)\end{array}$ & $\begin{array}{c}\text { ND } \\
(n=39)\end{array}$ & $\begin{array}{c}\text { UAO } \\
(n=11)\end{array}$ & $\begin{array}{l}\text { Heart disease } \\
\qquad(n=4)\end{array}$ & $\begin{array}{c}\text { DS } \\
(n=11)\end{array}$ \\
\hline $\begin{array}{l}\text { Age at the time of } \\
\text { admission (years) }\end{array}$ & $\begin{array}{c}2.2 \\
(0.6-8.8)\end{array}$ & $\begin{array}{c}5.5 \\
(1.4-12.6)\end{array}$ & $\begin{array}{c}0.8 \\
(0.5-12.4)\end{array}$ & $\begin{array}{c}4.6 \\
(1.2-9.5)\end{array}$ & $\begin{array}{c}0.7 \\
(0.3-1.0)\end{array}$ & $\begin{array}{c}0.9 \\
(0.3-3.0)\end{array}$ & $\begin{array}{c}1.5 \\
(0.6-2.2)\end{array}$ \\
\hline Sex (M/F) & $68 / 45$ & $14 / 11$ & $18 / 5$ & $19 / 20$ & $8 / 3$ & $2 / 2$ & $7 / 4$ \\
\hline $\begin{array}{l}\text { Mechanical } \\
\text { ventilation } \\
\text { (IV/NIV) }\end{array}$ & $33 / 37$ & $7 / 13$ & $4 / 5$ & $13 / 14$ & $4 / 3$ & $0 / 1$ & $5 / 1$ \\
\hline $\begin{array}{l}\text { Length of stay } \\
\text { (days) }\end{array}$ & $\begin{array}{c}16.0 \\
(6.5-49.0)\end{array}$ & $\begin{array}{c}7.0 \\
(3.0-63.5)\end{array}$ & $\begin{array}{c}14.0 \\
(6.0-35.0)\end{array}$ & $\begin{array}{c}30.0 \\
(10.0-63.0)\end{array}$ & $\begin{array}{c}13.0 \\
(6.0-61.0)\end{array}$ & $\begin{array}{c}9.5 \\
(5.3-14.5)\end{array}$ & $\begin{array}{c}20.0 \\
(13.0-79.0)\end{array}$ \\
\hline
\end{tabular}

NMD: neuromuscular disease; CLD: chronic lung disease; ND: neurological damage; UAO: upper airway obstruction; DS: Down syndrome; M: male; F: female; IV: invasive ventilation; NIV: non-invasive ventilation.

TABLE 2. Number of patients admitted by cause, by total group and pathology subgroups

\begin{tabular}{lccc}
\hline Diagnosis & Initiation of MV & Re-assessment & Post-exacerbation \\
\hline DS $(\mathrm{n}=11)$ & 11 & 6 & 5 \\
Heart disease $(\mathrm{n}=4)$ & 4 & 0 & 1 \\
UAO $(\mathrm{n}=11)$ & 11 & 4 & 6 \\
ND $(\mathrm{n}=39)$ & 36 & 15 & 23 \\
CLD $(\mathrm{n}=23)$ & 17 & 4 & 7 \\
NMD $(\mathrm{n}=25)$ & 20 & 36 & 8 \\
Total $(\mathrm{n}=113)$ & 99 & 56 \\
\hline
\end{tabular}

MV: mechanical ventilation; DS: Down syndrome; UAO: upper airway obstruction; ND: neurological damage;

CLD: chronic lung disease; NMD: neuromuscular disease. 
study period, 310 admissions were recorded among 113 patients, who accounted for a total of 10507 days of hospital stay, with an occupancy rate $>90 \%$ at the PMVU. This resulted in more available beds at the PICU for acute, critical patients and prevented lengthy stays among patients with high chronic respiratory technology dependency in said unit.

Our results were consistent with those reported by Paulides et al., who also documented lengthy hospital stays in this group of patients, which limited bed availability in pediatric critical care units. Their report shared a 30-year experience, with more than 300 ventilatordependent children, who were hospitalized during 12440 days before being discharged and sent home, and required 9335 hospitalization days due to severe readmissions to the PICU. ${ }^{3}$

A previous report made by our group confirmed that the implementation of the PMVU helped to increase rotation rates and reduce the length of stay at the PICU significantly. ${ }^{11}$ This was consistent with the findings of Amirnovin et al., who reported a decreased average length of stay at the PICU, from 70 to 36 days, with the implementation of a similar hospital strategy. ${ }^{5}$

The most common diagnoses were NMD, CLD, ND, and UAO; a significantly lower age at admission was observed among patients with UAO, and a higher age, among those with NMD. In the case of UAOs, this was related to the severity observed in patients during early life, since in our cohort of admitted UAO children younger than 1 year, $78 \%$ required tracheostomy and / or ventilation at home after discharge, as it was previously described in severe cases. However, many times, its final resolution entails maxillary or mandibular advancement surgery. ${ }^{13}$ Mandibular distraction was performed in $33 \%$ of our UAO patients younger than 1 year in order to avoid tracheostomy, a procedure which was previously reported in neonates with severe micrognathia and was shown to be safe and effective and reduce respiratory dependency. ${ }^{14,15}$

In order to optimize the ventilatory management of UAO patients younger than 1 year, NIV was used in $22 \%$ of cases, avoiding intubation and tracheostomy, as demonstrated by Leboulanger et al., in a cohort of newborn infants with Pierre Robin sequence, where they proposed considering this type of support as a first-line treatment. ${ }^{16}$

Home NIV was indicated in $63 \%$ of included NMD cases, which mainly corresponded to the slowly progressive NMD group, which required respiratory care and ventilatory support later on in life. ${ }^{17,18}$ Nowadays, there is consensus regarding the need to initiate NIV in an early manner in patients with progressive NMD, given the positive impact it has on its clinical course. ${ }^{17,18}$ Although the need for ventilatory support should be determined by observing sleep-disordered breathing, this therapy is frequently initiated after a hospitalization for a respiratory condition. ${ }^{18,19}$ This situation has been reported in the bibliography and will depend on the type of NMD, available treatments, and other related prognostic factors. ${ }^{18,20}$

Several countries have implemented strategies to provide home invasive and non-invasive ventilatory support, with a marked increase in the last 30 years, and favorable results have been observed both in patients and health care systems. ${ }^{3,4,11,21,22}$ In our group of children, those who met the required socioeconomic conditions at home were admitted to government programs implemented in Chile since 2006 for NIV and since 2008 for IV, which included 658 active pediatric patients and 1212 admitted patients at the beginning of $2019 .{ }^{8-10,23}$ For the group

TABLE 3. Length of hospital stay in days, number of readmissions, and reasons for readmission by type of mechanical ventilation

\begin{tabular}{|c|c|c|c|c|c|c|c|}
\hline \multirow{2}{*}{$\begin{array}{l}\text { Type of mechanical } \\
\text { ventilation }\end{array}$} & \multirow{2}{*}{$\begin{array}{c}\text { Length of stay } \\
\text { Days }\end{array}$} & \multicolumn{2}{|r|}{ Readmission } & \multicolumn{2}{|c|}{ Re-assessment } & \multicolumn{2}{|c|}{ Post-exacerbation } \\
\hline & & $\mathbf{n}$ & No. of admissions & $\mathbf{n}$ & No. of admissions & $\mathbf{n}$ & No. of admissions \\
\hline $\begin{array}{l}\text { IV } \\
(n=33)\end{array}$ & $\begin{array}{c}61,0 \\
(14,0-179,5)^{\mathrm{ab}}\end{array}$ & 21 & 73 & 11 & 15 & 18 & 54 \\
\hline $\begin{array}{l}\text { NIV } \\
(\mathrm{n}=37)\end{array}$ & $\begin{array}{c}14,0 \\
(5,0-35,8)^{a}\end{array}$ & 17 & 66 & 12 & 16 & 16 & 51 \\
\hline $\begin{array}{l}\text { Without MV } \\
(\mathrm{n}=43)\end{array}$ & $\begin{array}{c}13,0 \\
(7,3-30,8)^{b}\end{array}$ & 3 & 5 & 0 & 0 & 4 & 6 \\
\hline
\end{tabular}

Data expressed as median and interquartile range. IV: invasive ventilation; NIV: non-invasive ventilation; MV: mechanical ventilation. $a, b: p<0.05$ between assessed outcome measures by type of mechanical ventilation. 
of patients who did not meet the required socioeconomic conditions for this programs in order to go back home with ventilatory support, a technical and professional team was introduced in an institution external to the hospital..$^{8-10,24}$

Of all children included in our study, $54 \%$ required an unscheduled readmission to the PMVU, most of them with IV, which may be explained by their highly complex underlying conditions, associated complications, and the need for regular assessments in order to determine behaviors that may suggest an advancement or regression of their underlying condition..$^{25-27}$ Kun et al., described unscheduled readmissions in patients with home IV and reported $40 \%$ readmissions 12 months after hospital discharge, of which $64 \%$ were related to respiratory reasons..$^{25}$ Results were similar in our group of children with home IV: $30 \%$ had an unscheduled readmission in the first year, and $67 \%$ of them were due to respiratory reasons.

Scheduled readmissions were also more common among IV children, who generally had limitations to undergo multiple checkups and tests. Individualized plans were elaborated, according to clinical condition and specific problems. Specialist assessment, upper airway assessment, sleep studies, and general examinations were mainly included. Henningfeld et al., described a ventilation weaning and decannulation process in 46 children with IV, which entailed hospital admission and tests in order to plan it and achieve a higher success rate. ${ }^{27,28}$ This was done in 6 of our children who were on IV for less than three years since tracheostomy was done, and liberation from the ventilator was more common before 5 years since its initiation. ${ }^{28}$

Our study has certain limitations, such as the variety of categorized pathologies and their sample size, which limits comparisons among them. The study was exclusively conducted in our hospital; therefore, it only allowed to show the local reality with a limited number of participants, which may have affected the results of our analysis. Nevertheless, to date, there are no reports on the national situation in Chile, and international reports on this type of care dependency are scarce. In addition, comorbidity severity and the socioeconomic characteristics of our population were not included as potential confounding factors.

\section{CONCLUSION}

Based on the results of this study, it may be concluded that unscheduled readmissions are common at our PMVU; these are mainly for respiratory reasons and IV-related. At the same time, all patients managed at the PMVU were successfully discharged from the hospital, regardless of the complexity of their conditions. At a local level, developing a unit specialized in the respiratory care of patients with high respiratory technology dependency resulted in more available PICU beds for acute, critical patients.

\section{Acknowledgments}

We would like to thank the entire health care team caring for patients with high respiratory dependency at the PMVU, the intensive care unit, and patients' homes. We would also like to thank patients' parents and family members, who live through their days with a spark of hope, trying to improve the life expectancy of these children.

\section{REFERENCES}

1. Elias ER, Murphy NA, Liptak GS, Adams RC, et al. Home care of children and youth with complex health care needs and technology dependencies. Pediatrics. 2012;129(5):996-1005.

2. Torres-Castro R, Zenteno D, Rodriguez-Nuñez I, Villarroel $\mathrm{G}$, et al. Guías de rehabilitación respiratoria en niños con enfermedades respiratorias crónicas: actualización 2016. Neumol Pediatr. 2016; 11(3):114-31.

3. Paulides F, Plötz RB, Verweij-van den Oudenrijn LP, Van GestelJPJ, et al. Thirty years of home mechanical ventilation in children: Escalating need for pediatric intensive care beds. Intensive Care Med. 2012; 38(5):847-52.

4. Amin R, Sayal A, Syed F, Daniels C, et al. How long does it take to initiate a child on long-term invasive ventilation? Results from a Canadian pediatric home ventilation program. Can Respir J. 2015; 22(2):103-8.

5. Amirnovin R, Aghamohammadi S, Riley C, Woo MS, et al. Analysis of a pediatric home mechanical ventilator population. Respir Care. 2018; 63(5):558-64.

6. Sauthier M, Rose L, Jouvet P. Pediatric prolonged mechanical ventilation: Considerations for definitional criteria. Respir Care. 2017; 62(1):49-53.

7. Moore PE, BoyerD, $\mathrm{O}^{\prime}$ Connor MG, Baker CD, et al. Pediatric chronic home invasive ventilation. Ann Am Thorac Soc. 2016; 13(7):1170-2.

8. Chile. Ministerio de Salud, Subsecretaría de Redes Asistenciales, División de Atención Primario, Unidad de Salud Respiratoria. Programa de Asistencia Ventilatoria No Invasiva en Atención Primaria de Salud: Normas Técnicas. Neumonol Pediatr. 2007; 2:38-48.

9. Chile. Ministerio de Salud, Subsecretaría de Redes Asistenciales, División de AtenciónPrimario, Unidad deSalud Respiratoria. Protocolo de Ventilación Mecánica Invasiva en APS. 2013. [Accessed on:July31 $\left.{ }^{\text {st }}, 2020\right]$. Availableat: https: / / respiratorio.minsal.cl/PDF/AVNI/Progama_AVI_2013.pdf.

10. Maquilón OC, Antolini TM. Jornadas de otoño 2019 “De la UCI al domicilio". Rev Chil Enferm Respir. 2019; 35(2):93-5.

11. Galaz SN, Zenteno AD, Barraza EC, Tapia ZJ, et al. Impact of a prolonged ventilation unit in pediatric service. XI 
SOLANEP International Congress/XV Cystic Fibrosis Latinamerican Congress/XV Brazilian Congress of Pediatric Pulmonology. Pediatr Pulmonol.2016;51(S42):180.

12. Von Elm E, Altman D, Egger M, Pocock S, et al. The Strengthening the Reporting of Observational Studies in Epidemiology (STROBE) statement: guidelines for reporting observational studies. J Clin Epidemiol. 2008; 61(4):344-9.

13. TanHL, Kheirandish-Gozal L, AbelF, Gozal D. Craniofacial syndromes and sleep-related breathing disorders. Sleep Med Rev. 2016; 27:74-88.

14. Denny A, Amm C. New technique for airway correction in neonates with severe Pierre Robin sequence. J Pediatr. 2005; 147(1):97-101.

15. Hong P. A clinical narrative review of mandibular distraction osteogenesis in neonates with Pierre Robin sequence. Int J Pediatr Otorhinolaryngol. 2011; 75(8):985-91.

16. Leboulanger N, Picard A, Soupre V, Aubertin G, et al. Physiologic and Clinical Benefits of Noninvasive Ventilation in Infants with Pierre RobinSequence. Pediatrics. 2010; 126(5):e1056-63.

17. Birnkrant DJ, Bushby K, Bann CM, Alman BA, et al. Diagnosis and management of Duchenne muscular dystrophy, part 2: respiratory, cardiac, bone health, and orthopaedic management. Lancet Neurol. 2018; 17(4):34761.

18. HullJ, AniapravanR, ChanE,ChatwinM, etal.British Thoracic Society guidelinefor respiratory management of children with neuromuscular weakness. Thorax. 2012; 67(Suppl 1):i1-40.

19. Amaddeo A, Moreau J, Frapin A, Khirani S, et al. Long term continuous positive airway pressure (CPAP) and noninvasive ventilation (NIV) in children: Initiation criteria in real life. Pediatr Pulmonol. 2016; 51(9):968-74.
20. Zenteno AD, Verbal CD, Barraza EC, Elso TMJ. Estudios de sueño en pacientes con enfermedades neuromusculares. Neumol Pediatr. 2017; 12(2):76-80.

21. Chau SK, Yung AW, Lee SL. Long-Term Management for Ventilator-Assisted Children in Hong Kong: 2 Decades' Experience. Respir Care. 2017; 62(1):54-64.

22. Amin R, SayalP, Syed F, Chaves A, elal. Pediatriclong-term home mechanical ventilation: Twenty years of follow-up from one Canadian center. Pediatr Pulmonol. 2014;49(8):81624.

23. Prado AF, Salinas FP. Asistencia ventilatoria no invasiva domiciliaria en niños: Impacto inicial de un programa nacional en Chile. Rev Chil Pediatr. 2011; 82(4):289-99.

24. Carrasco D, Navarro X, Herrera C, Tapia J, et al. Ventilación mecánica prolongada en la corporación nacional de nutrición infantil (CONIN)... La Luz no se apaga. Neumol Pediatr. 2017; 12(4):A196.

25. Kun SS, Edwards JD, Davidson Ward SL, Keens TG. Hospital readmissions for newly discharged pediatric home mechanical ventilation patients. Pediatr Pulmonol. 2012; 47(4):409-14.

26. Edwards JD, Kun SS, Keens TG. Outcomes and Causes of Death in Children on Home Mechanical Ventilation via Tracheostomy: An Institutional and Literature Review. J Pediatr. 2010; 157(6):955-9.e2.

27. Henningfeld JK, Maletta K, Ren B, Richards KL, et al. Liberation from home mechanical ventilation and decannulation in children. Pediatr Pulmonol.2016;51(8):83849.

28. Gurbani N, Promyothin U, Rutter M, Fenchel MC, et al. Using Polysomnography and Airway Evaluation to Predict Successful Decannulation in Children. Otolaryngol Head Neck Surg. 2015; 153(4):649-55. 